\title{
Comparative Evaluation of Flexural Strength and Modulus of Elasticity of Three Adhesive Luting Cements at Different Time Intervals under Oral Simulated Conditions: An In Vitro Study
}

\author{
Sumedha Dewan ${ }^{1}$ Tarun Kalra ${ }^{1}$ Manjit Kumar ${ }^{1} \quad$ Ajay Bansal $^{1} \quad$ Abhishek Avasthi $^{1}$
}

1Department of Prosthodontics, Bhojia Dental College and Hospital, Solan, Himachal Pradesh, India

Address for correspondence Manjit Kumar, MDS, Department of Prosthodontics, Bhojia Dental College and Hospital, Solan - 173205, Himachal Pradesh, India (e-mail: manjitkiran@yahoo.co.in).

Dent J Adv Stud 2021;9:70-76.

\begin{abstract}
Keywords

- adhesive cements

- dual-cure cements

- flexural strength

- modulus of elasticity

Aim The purpose of this study was to compare and evaluate the flexural strength and modulus of elasticity of three adhesive luting cements as a function of specimen age, effect of storage media, and effect of curing through porcelain.

Materials and Methods Twenty samples fabricated for self-cure resin-modified glass ionomer cement (GIC; RelyX Luting 2, 3M ESPE, United States) were classified as group 1, whereas 40 samples fabricated for two dual-cure resin cements (20 samples each), Universal Resin Cement (Ammdent, Italy) and Maxcem Elite (Kerr Australia Pty. Ltd.), were classified as groups 2 and 3, respectively. The dual-cure cements were photo-activated using light cure unit with an intensity of $550 \mathrm{~mW} / \mathrm{cm}^{2}$ in nine overlapping sections for 20 seconds per section on both sides. A total of 60 samples (20 samples in each group) were fabricated and tested using universal testing machine to compare flexural strength and modulus of elasticity of resin-modified GIC with two dual-cure adhesive resin cements, to determine the influence of storage of the specimens in artificial saliva at $37^{\circ} \mathrm{C}$ for 24 hours and to determine the influence of curing through porcelain disk of $2 \mathrm{~mm}$ thickness on these properties.

Results The overall mean flexural strength and modulus of elasticity of resin-modified GIC was less than the dual-cure resin cements. The values reduced for resin-modified GIC when the samples were tested after 24 hours of storage in saliva, whereas an increase in the strength was seen for dual-cure cements. The curing through porcelain disk reduced the properties of dual-cure cements. Maxcem Elite showed better overall mean flexural strength and modulus of elasticity in all the parameters.

Conclusion When comparing all three cements, both dual-cure cements showed better flexural strength and modulus of elasticity compared to resin-modified GIC, which indicates their use in cementation of fixed restorations.
\end{abstract}

DOI https://doi.org/ $10.1055 / \mathrm{s}-0041-1731104$ ISSN 2321-1482
(C) 2021. Bhojia Dental College and Hospital affiliated to Himachal Pradesh University.

This is an open access article published by Thieme under the terms of the Creative Commons Attribution-NonDerivative-NonCommercial-License, permitting copying and reproduction so long as the original work is given appropriate credit. Contents may not be used for commercial purposes, or adapted, remixed, transformed or built upon. (https://creativecommons.org/licenses/by-nc-nd/4.0/).

Thieme Medical and Scientific Publishers Pvt. Ltd. A-12, 2nd Floor, Sector 2, Noida-201301 UP, India 


\section{Introduction}

Luting agents help in bonding between the restoration and prepared tooth, either mechanically, micromechanically, chemically, or in combination. ${ }^{1}$ An ideal luting agent must exhibit mechanical properties that can withstand masticatory and parafunctional stresses for a long time in a warm and wet oral environment. The tensile, shear, and compressive strengths play less role compared to the flexural properties of these materials because resin-bonded fixed partial denture (FPDs) are likely to be subjected more to the bending forces than to other types of stress. ${ }^{2}$

Glass ionomer cements (GIC, or glass polyalkenoate cements) were developed in 1969 by Wilson and Kent. Their advantages include bonding to both enamel and dentin and their property of fluoride release, which is known to be anticariogenic. The primary disadvantage of this cement is its slow maturation process (24-72 hours after placement), moisture sensitivity, and insufficient wear resistance. ${ }^{1}$

Then resin-modified GIC and compomers evolved from GIC in 1990s combining some desirable properties of GIC and resin composites (fluoride release and chemical adhesion) with high strength and low solubility. They have the advantage of improved compressive strength, diametral tensile structure, and flexural strength in comparison to zinc phosphate, polycarboxylate, and glass ionomer with the disadvantage of increased water sorption and frequent plasticity due to the hydrophilic nature of the poly-hydroxyl-ethyl-methacrylate (poly-HEMA) component, which leads to "hygroscopic expansion." Though water sorption compensates polymerization shrinkage, if continuous, it may lead to dimensional changes. ${ }^{3}$

Light cure cements have restricted indication to laminate veneers. Because of the severe reduction of light intensity during its transmission through the restoration, dual-cured cements were developed to combine the characteristics of self-cured and photo-activated cements. The elastic modulus of the luting cements should be close to dentin so that there is less concentration of stress at the cement-tooth interface. ${ }^{2}$

Ample polymerization is a must for optimal mechanical strength and clinical performance of a particular luting agent. The light intensity of light cure source decreases with time and leads to less degree of polymerization. This has an impact on thick restorations that require cementation. In these cases, use of dual-cure cement has disadvantages. There is less degree of conversion and less hardness. ${ }^{4}$

This study was undertaken to compare the flexural strength and the modulus of elasticity of resin-modified GIC with dual-cure adhesive resin cements in terms of the effect of artificial saliva after 24 hours of fabrication of specimen, and influence of curing through porcelain disk on the properties of these cements.

\section{Materials and Method}

\section{Fabrication of Mold}

A glass plate of 2-mm thickness was taken and cut into sections such that it allowed for the necessary width of $2 \mathrm{~mm}$ and thickness of $2 \mathrm{~mm}$, and length of $25 \mathrm{~mm}$ (according to ISO 4049; - Fig. 1).

\section{Fabrication of Porcelain Disk}

Dual-cure adhesive cements are used clinically to lute porcelain restorations. Thus, in order to simulate similar conditions, a porcelain disk of $2 \mathrm{~mm}$ was fabricated through which the specimens were light cured. To fabricate the porcelain disk, wax pattern was fabricated on the light tip of light cure unit using blue modeling wax. This wax pattern was utilized to fabricate the porcelain disk using lithium disilicate glass ceramic ingot in a pressable porcelain furnace (-Fig. 2 ).

\section{Curing Protocol}

The light source was placed at the center of the specimen for 20 seconds and then moved to the side along the length of the specimen and the whole length of the specimen was cured

\section{Fabrication of Specimens}

\section{Group 1: Self-cure resin-bonded glass ionomer cement}

Prior to specimen fabrication, the glass mold was sprayed with a separating agent for ease of specimen removal. The

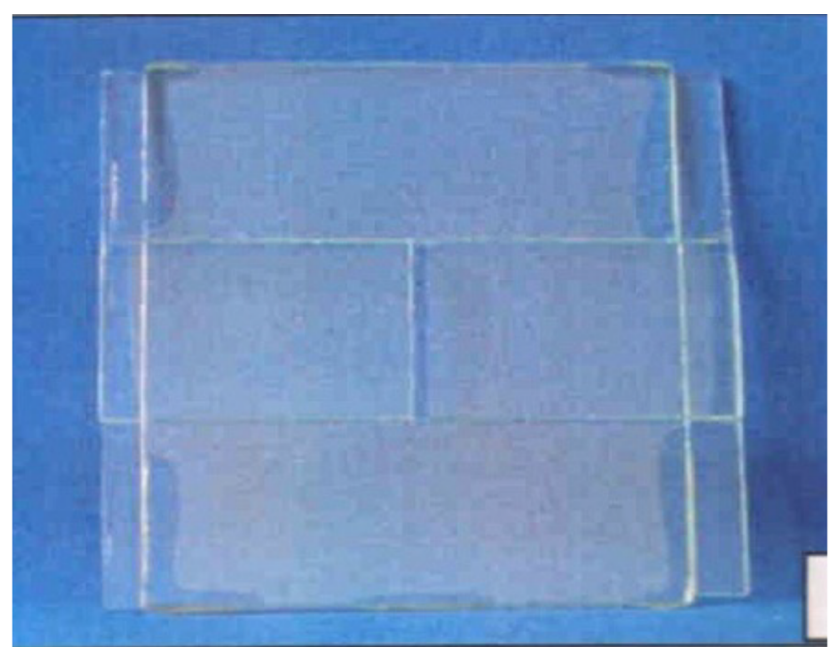

Fig. 1 Fabrication of glass mold.

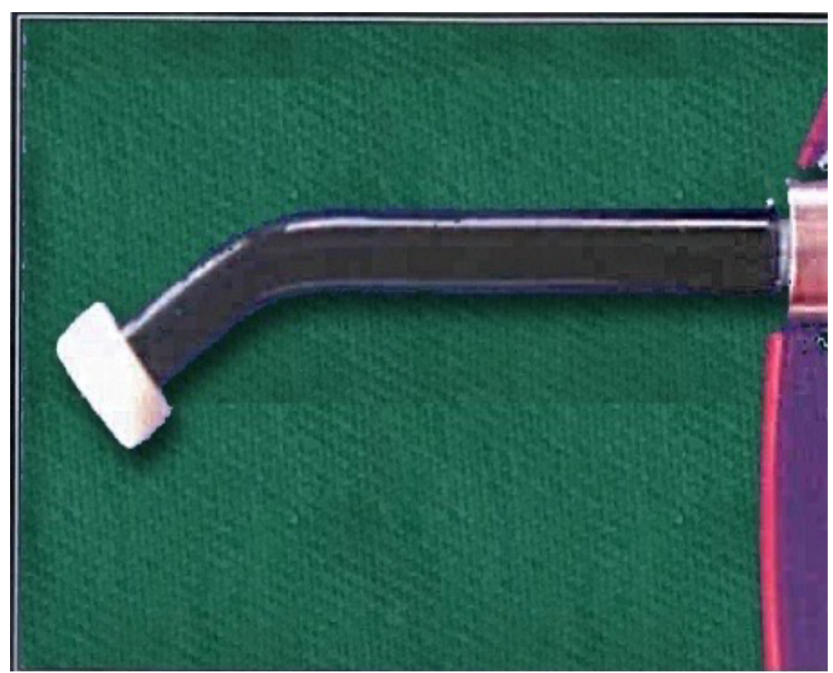

Fig. 2 Porcelain disk fabricated for light cure tip. 
base and the catalyst were mixed and loaded into the rectangular portion of the mold using plastic filling instrument (-Fig. 3).

The specimens were retrieved, finished, and polished and were subjected to different storage protocols as mentioned in - Table 1.

Group 2: Dual-cure resin cement (Universal Resin Cement)

The material was mixed (manufacturer's instructions) and loaded similarly. The specimen was then photo-activated using light cure unit with an intensity of $550 \mathrm{~mW} / \mathrm{cm}^{2}$ in nine overlapping sections for 20 seconds per section on both sides (with and without porcelain disk) according to the curing and storage protocols for each subgroup as mentioned in

-Table 2 (-Fig. 4).

Group 3: Maxcem Elite (Kerr Australia Pty. Ltd.)

Specimens were fabricated similarly to group 2 and tested according to the curing and storage protocols for each subgroup as mentioned in - Table $\mathbf{3}$ ( $\mathbf{- F i g . 5}$ ).

\section{Fabrication of "Three-Point Bending Platform"}

To carry out the test with a universal testing machine, a custom-made platform was fabricated. A metal plate was taken and two metal round bars of 2-mm diameter were soldered on this base $20 \mathrm{~mm}$ apart.

\section{Artificial Saliva}

The artificial saliva used in the present study was prepared according to the Macknight-Hane and Whitford formula (1992). The composition of artificial saliva (in grams per liter) is as follows: methyl-p-hydroxybenzoate $2.00 \mathrm{~g}$, sodium carboxymethyl cellulose $10.00 \mathrm{~g}, \mathrm{KCl} 0.625 \mathrm{~g}, \mathrm{MgCl}_{2} \cdot 6 \mathrm{H}_{2} \mathrm{O} 0.052 \mathrm{~g}$, $\mathrm{CaCl}_{2} \cdot 2 \mathrm{H}_{2} \mathrm{O} 0.166 \mathrm{~g}, \mathrm{~K}_{2} \mathrm{HPO}_{4} 0.804 \mathrm{~g}$, and $\mathrm{KH}_{2} \mathrm{PO}_{4} 0.326 \mathrm{~g}$. The pH was set to 6.75 with $\mathrm{KOH}$ (-Fig. 6).

\section{Testing of the Specimens}

The stored specimens were removed from the artificial saliva and tested after blotting dry. A compressive load was applied to the specimen at a cross-head speed of $1 \mathrm{~mm} / \mathrm{min}$ using $50-\mathrm{kg}$ load cell. The bending data were recorded as load to displacement ( - Fig. 7).

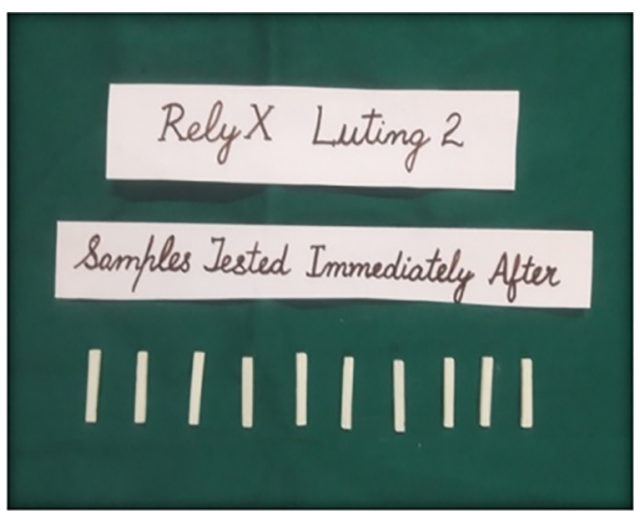

Table 1 Curing and storage protocol: self-cure resin bonded glass ionomer cement

\begin{tabular}{|l|l|l|}
\hline Groups & $\begin{array}{l}\text { Curing } \\
\text { protocol }\end{array}$ & Storage protocol \\
\hline $\begin{array}{l}\text { Group } \\
1 \mathrm{~A}\end{array}$ & Self-cure & Tested immediately \\
\hline $\begin{array}{l}\text { Group } \\
1 \mathrm{~B}\end{array}$ & Self-cure & $\begin{array}{l}\text { Tested after storing for } 24 \mathrm{~h} \text { in } \\
\text { artificial saliva at } 37^{\circ} \mathrm{C}\end{array}$ \\
\hline
\end{tabular}

Table 2 Curing and storage protocol: dual cure resin cement

\begin{tabular}{|l|l|l|}
\hline Groups & $\begin{array}{l}\text { Curing } \\
\text { protocol }\end{array}$ & Storage protocol \\
\hline $\begin{array}{l}\text { Group } \\
\text { 2A }\end{array}$ & $\begin{array}{l}\text { Without por- } \\
\text { celain disk }\end{array}$ & Tested immediately \\
\hline $\begin{array}{l}\text { Group } \\
\text { 2B }\end{array}$ & $\begin{array}{l}\text { Without por- } \\
\text { celain disk }\end{array}$ & $\begin{array}{l}\text { Tested after storing for } 24 \mathrm{~h} \text { in } \\
\text { artificial saliva at } 37^{\circ} \mathrm{C}\end{array}$ \\
\hline $\begin{array}{l}\text { Group } \\
\text { 2C }\end{array}$ & $\begin{array}{l}\text { With porce- } \\
\text { lain disk }\end{array}$ & Tested immediately \\
\hline $\begin{array}{l}\text { Group } \\
\text { 2D }\end{array}$ & $\begin{array}{l}\text { With porce- } \\
\text { lain disk }\end{array}$ & $\begin{array}{l}\text { Tested after storing for } 24 \mathrm{~h} \text { in } \\
\text { artificial saliva at } 37^{\circ} \mathrm{C}\end{array}$ \\
\hline
\end{tabular}

Table 3 Curing and storage protocol: Maxcem Elite

\begin{tabular}{|l|l|l|}
\hline Groups & $\begin{array}{l}\text { Curing } \\
\text { protocol }\end{array}$ & Storage protocol \\
\hline $\begin{array}{l}\text { Group } \\
\text { 3A }\end{array}$ & $\begin{array}{l}\text { Without por- } \\
\text { celain disk }\end{array}$ & Tested immediately \\
\hline $\begin{array}{l}\text { Group } \\
\text { BB }\end{array}$ & $\begin{array}{l}\text { Without por- } \\
\text { celain disk }\end{array}$ & $\begin{array}{l}\text { Tested after storing for } 24 \mathrm{~h} \text { in } \\
\text { artificial saliva at } 37^{\circ} \mathrm{C}\end{array}$ \\
\hline $\begin{array}{l}\text { Group } \\
\text { 3C }\end{array}$ & $\begin{array}{l}\text { With porce- } \\
\text { lain disk }\end{array}$ & Tested immediately \\
\hline $\begin{array}{l}\text { Group } \\
\text { 3D }\end{array}$ & $\begin{array}{l}\text { With porce- } \\
\text { lain disk }\end{array}$ & $\begin{array}{l}\text { Tested after storing for } 24 \mathrm{~h} \text { in } \\
\text { artificial saliva at } 37^{\circ} \mathrm{C}\end{array}$ \\
\hline
\end{tabular}

The flexural strength was calculated from fracture load and specimen dimensions according to the following formula:

Flexural strength $=\frac{3 \times \text { fracture load } \times \text { support span length }}{2 \times \text { width } \times \text { thickness }^{2}}$

From Hook's law, the modulus of elasticity is defined as the ratio of the stress to the strain:

$$
E=\frac{(\sigma) \text { STRESS }}{(\dot{g}) \text { STRAIN }}
$$

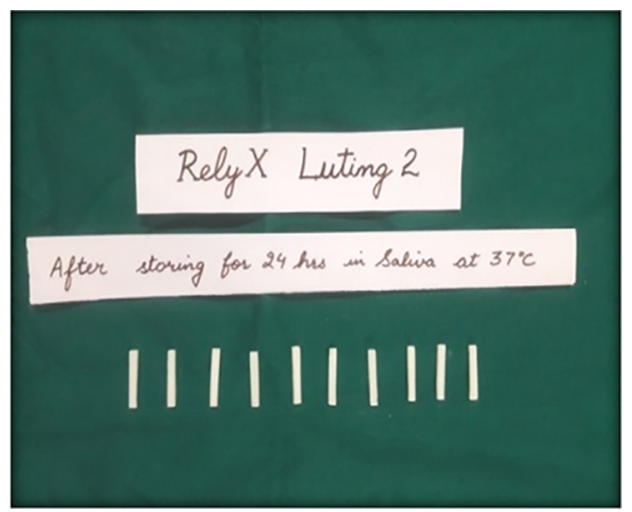

Fig. 3 Group 1: resin-modified glass ionomer cement (RelyX Luting 2) and subgroups. 

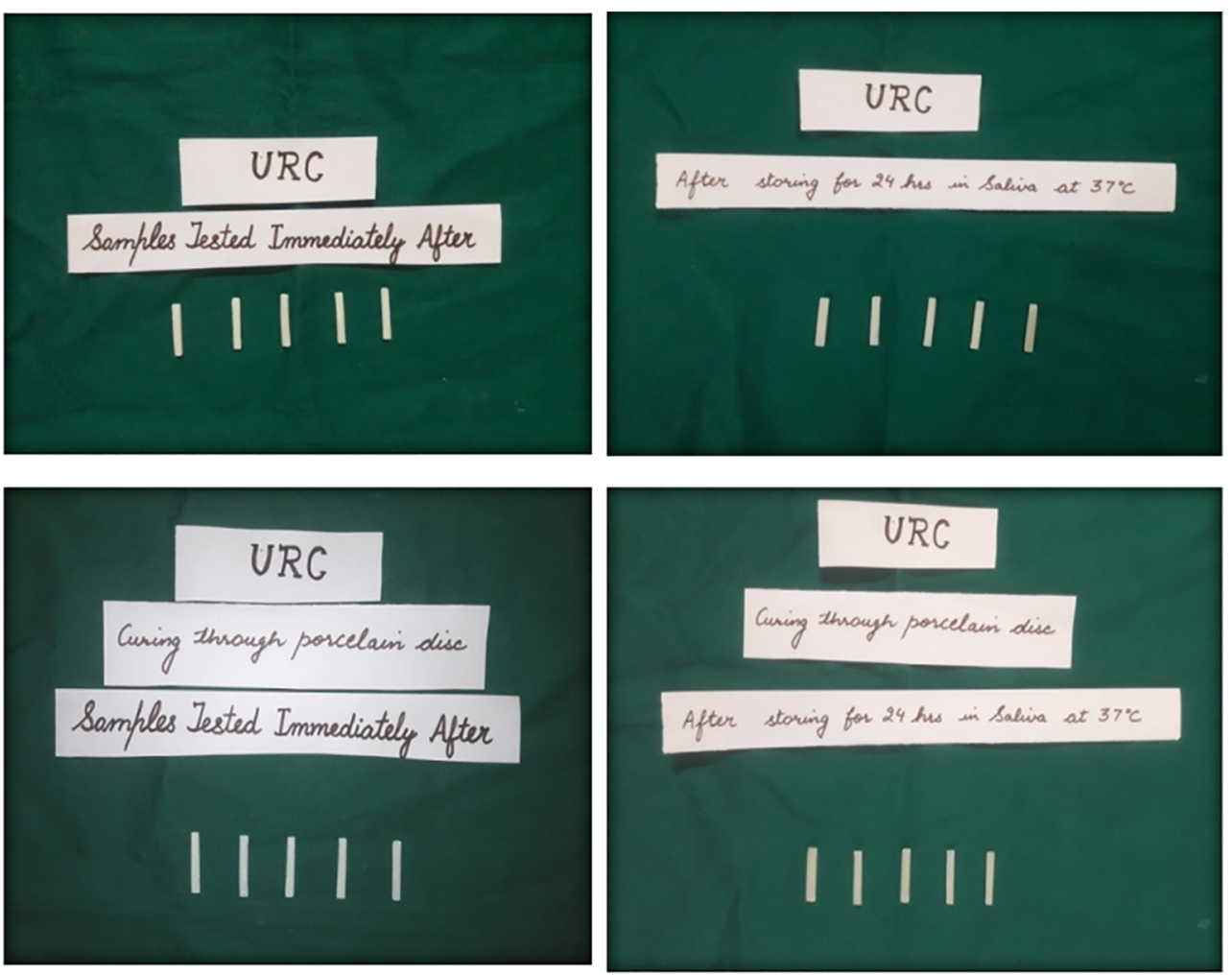

Fig. 4 Group 2: dual-cure adhesive resin cement (URC) and subgroups.
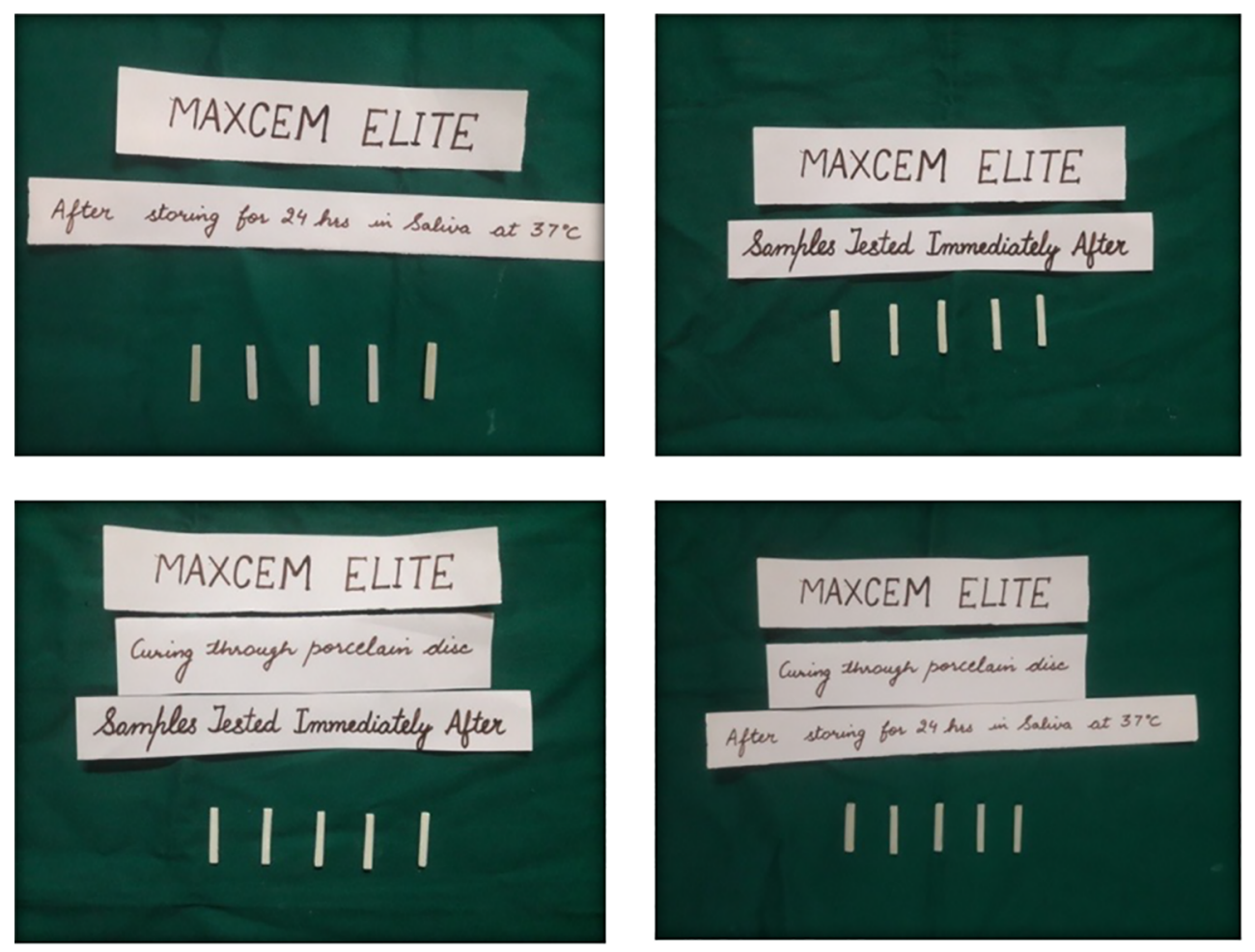

Fig. 5 Group 3: dual-cure adhesive resin cement (Maxcem Elite) and subgroups.

\section{Data Collection and Statistical Analysis}

The data obtained were statistically analyzed and the mean, standard deviation, and standard error were calculated for each group. One way analysis of variance (ANOVA), post hoc tests, and $t$-tests were done to statistically analyze the data.

\section{Observation and Results}

On comparison of mean flexural strength (in megapascals) among the three groups, it was clear that the highest mean flexural strength was obtained for group 3D Maxcem Elite when cured without porcelain disk and stored in saliva for 


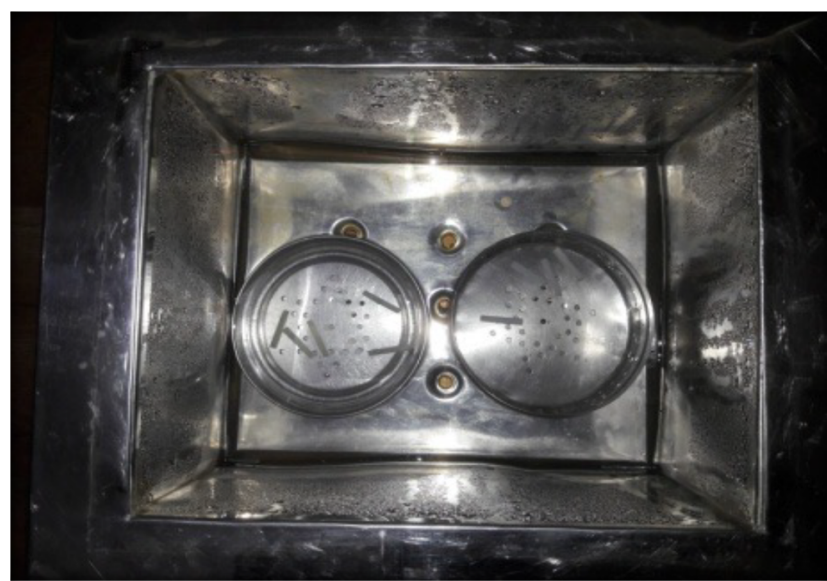

Fig. 6 Samples dipped in artificial saliva in water bath at $37^{\circ} \mathrm{C}$.

24 hours (142.59 MPa) and the least mean flexural strength was obtained for group 1B RelyX Luting 2 when it was tested immediately after self-curing (30.06 MPa).

The decreasing values of flexural strength were as follows: $3 \mathrm{D}>2 \mathrm{D}>3 \mathrm{C}>2 \mathrm{C}>2 \mathrm{~B}>3 \mathrm{~B}>3 \mathrm{~A}>2 \mathrm{~A}>1 \mathrm{~A}>1 \mathrm{~B}$.

When groups $2 \mathrm{~A}, 3 \mathrm{C}$, and $3 \mathrm{D}$ were compared, there was statistically no difference between them ( - Table 4 and $\boldsymbol{-}$ Fig. 8 ).

On comparison of mean modulus of elasticity (in gigapascals) among the three groups, it was observed that the highest mean of modulus of elasticity was obtained for group 2D Universal

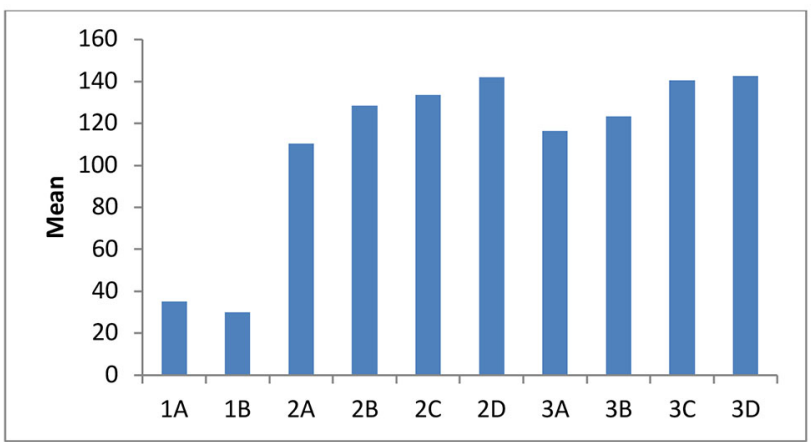

Fig. 8 Comparison of mean flexural strength (in MPa) among the three groups.

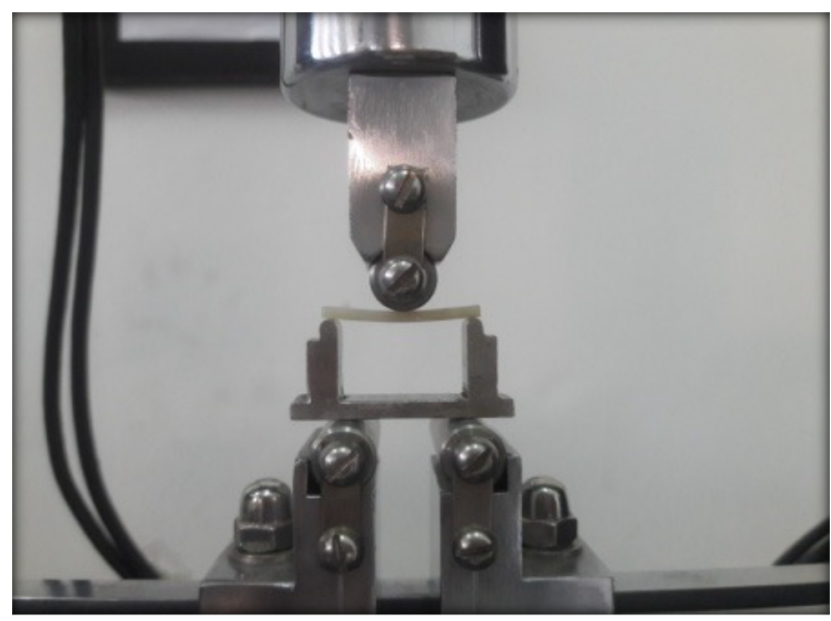

Fig. 7 Testing flexural strength using three-point bending platform.

Resin Cement (URC) when cured without porcelain disk and stored in saliva for 24 hours (11.95 GPa) and the least mean of modulus of elasticity was obtained for group 1B RelyX Luting 2 when tested after 24 hours of storage in saliva (5.31 GPa).

Groups 1A and 1B were statistically similar (5.95 and 5.31 $\mathrm{GPa})$; groups $2 \mathrm{~A}, 2 \mathrm{C}$, and $3 \mathrm{~A}$ were also statistically similar (8.71, 9.25, and $8.95 \mathrm{GPa}$ ); and groups $2 \mathrm{~B}, 2 \mathrm{D}, 3 \mathrm{~B}$, and 3D were statistically similar $(11.61,11.95,11.91$, and $11.17 \mathrm{GPa})$. The decreasing values of modulus of elasticity were as follows: $2 \mathrm{D}>3 \mathrm{~B}>$ $2 \mathrm{~B}>3 \mathrm{D}>3 \mathrm{C}>2 \mathrm{C}>3 \mathrm{~A}>2 \mathrm{~A}>1 \mathrm{~A}>1 \mathrm{~B}$ (-Table 5 and - Fig. 9).

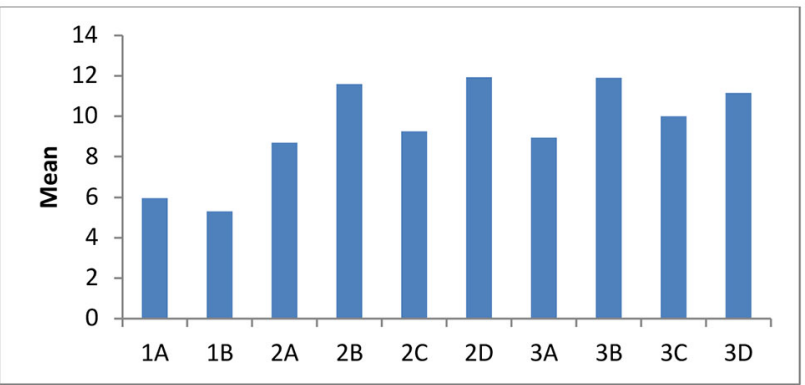

Fig. 9 Comparison of mean modulus of elasticity (in GPa) among the three groups.

Table 4 -Value of tested samples

\begin{tabular}{|c|c|c|c|c|}
\hline Group & Mean & SD & Anova test & $p$-Value \\
\hline $1 \mathrm{~A}$ & $35.02^{\mathrm{a}}$ & 0.93 & \multirow[t]{10}{*}{104.91} & \multirow[t]{10}{*}{$<0.01^{*}$} \\
\hline 1B & $30.06^{b}$ & 1.14 & & \\
\hline $2 \mathrm{~A}$ & $110.33^{c}$ & 3.96 & & \\
\hline $2 B$ & $128.51^{d}$ & 1.28 & & \\
\hline $2 C$ & $133.75^{\mathrm{e}}$ & 3.84 & & \\
\hline $2 \mathrm{D}$ & $142.09^{f}$ & 2.54 & & \\
\hline $3 \mathrm{~A}$ & $116.58^{g}$ & 3.83 & & \\
\hline $3 B$ & $123.32^{\mathrm{h}}$ & 2.21 & & \\
\hline $3 C$ & $140.44^{f}$ & 3.39 & & \\
\hline $3 \mathrm{D}$ & $142.59^{f}$ & 2.04 & & \\
\hline
\end{tabular}

Abbreviation: ANOVA, analysis of variance; SD, standard deviation.

*Statistically significant.

a-hTukey's honestly significant difference post hoc test; values with different letters indicate statistically significant difference as $p<0.05$. 
Table 5 Tukey HSD post hoc test values

\begin{tabular}{|c|c|c|c|c|}
\hline Group & Mean & SD & Anova test & $p$-Value \\
\hline $1 \mathrm{~A}$ & $5.95^{\mathrm{a}}$ & 0.95 & \multirow[t]{10}{*}{88.13} & \multirow[t]{10}{*}{$<0.01^{*}$} \\
\hline $1 \mathrm{~B}$ & $5.31^{\mathrm{a}}$ & 1.24 & & \\
\hline $2 A$ & $8.71^{b}$ & 1.85 & & \\
\hline $2 B$ & $11.61^{c}$ & 0.55 & & \\
\hline $2 C$ & $9.25^{b}$ & 1.23 & & \\
\hline $2 \mathrm{D}$ & $11.95^{c}$ & 2.19 & & \\
\hline $3 \mathrm{~A}$ & $8.95^{\mathrm{b}}$ & 1.13 & & \\
\hline $3 B$ & $11.91^{c}$ & 1.03 & & \\
\hline $3 C$ & $10.02^{\mathrm{d}}$ & 1.89 & & \\
\hline $3 D$ & $11.17^{c}$ & 1.77 & & \\
\hline
\end{tabular}

Abbreviation: ANOVA, analysis of variance; SD, standard deviation.

* Statistically significant.

a-dTukey's honestly significant difference post hoc test; values with different letters indicate statistically significant difference as $p<0.05$.

\section{Discussion}

Resin cements not only have excellent aesthetic shade-matching potential but also have better mechanical, physical, and adhesive properties, compared to conventional luting cements. ${ }^{5}$ Resin cements with improved physical characteristics have better fracture resistance, more retention of prosthesis, less micro-leakage, low water solubility.

In the present study, the resin-modified GIC group was represented by RelyX Luting 2, which is a self-curing, radiopaque, fluoride-releasing, resin-modified glass ionomer luting cement. The dual-cure resin cement group was represented by URC (Ammdent), which is available as an automix syringe. The viscosity of the cement is ideally suited for luting application. The other material in the dual-cure group is Maxcem Elite, which is a self-etch, self-adhesive, and dual-cure resin cement.

In the present study, the entire length of the specimen (25 mm) was done in nine overlapping sections as the light cure tip diameter used was $8 \mathrm{~mm}$. This is done according to Bhamra and Fleming ${ }^{6}$ who suggested that 8-, 11- and 13-mm light tip diameters require 9,7 , and 5 overlapping irradiations on each side to adequately polymerize the 25-mm length of the bar-shaped specimen. In the present study, the light curing of half of the dual-cure adhesive cements was done through a 2-mm thick porcelain disk of lithium disilicate, which was used to simulate all ceramic restorations, and it was found that the specimens showed decreased flexural strength and modulus of elasticity when they were cured through the porcelain disk. Mean flexural strength and modulus of elasticity of URC decreased from 133.75 MPa/9.25 GPa to $110.33 \mathrm{MPa} / 8.71 \mathrm{GPa}$ and that for MaxcemElite decreased from $140.44 \mathrm{MPa} / 10.02 \mathrm{GPa}$ to $116.58 \mathrm{MPa} / 8.95 \mathrm{GPa}$ when cured through porcelain disk and tested immediately. The result of the present study corroborated with the findings of the study carried out by Meng et $\mathrm{al}^{7}$ which showed that dual-cure luting cements with direct irradiation produced the best mechanical properties and polymer structure. This may be because the light intensity reaching the cement drastically reduces when the light is transmitted through a ceramic or composite restoration. According to a study by Blackman et $\mathrm{al}^{8}$ porcelain absorbs 40 to $50 \%$ of the curing light and increased porcelain thickness requires increased exposure times for resin curing. It may be suggested that clinically to compensate for this decrease in the flexural strength of dual-cure resins, the duration of light exposure should be increased from that which is recommended by the manufacturer, as has been suggested by studies.

In the present study, 30 specimens were tested immediately after fabrication and 30 were stored in artificial saliva for 24 hours before being checked for flexural strength and modulus of elasticity. This was done to compare the effect of immediate and storage in artificial saliva on the flexural strength of the three cements. The samples were kept in artificial saliva to simulate the oral environment. Dental cements are exposed to a variety of microorganisms in the oral cavity which produces acids and ferment the carbohydrates. The temperature and acid level of oral cavity keeps on changing.

The results were in accordance with Wadambe et $\mathrm{al}^{9}{ }^{9}$ Yap $^{10}$ and Pace et $\mathrm{al}^{11}$ whose results showed that a higher water sorption of resin-modified GIC was noticed compared to other resin luting agents. Monomer component and HEMA lead to hygroscopic expansion. Water sorption causes plasticizing effect, debonding matrix, and hydrolytic degeneration and reduces mechanical properties.

Hygroscopic expansion may be considered a favorable property, as its initial effect may contribute to the compensation for any polymerization shrinkage. But increased amount of water sorption can lead to unfavorable forces acting on the tooth structure and the restoration. On the contrary, the flexural strength and modulus of elasticity for dual-cure cements were superior after their storage in saliva. The results were in accordance with the observation by Pace et al. ${ }^{11}$ The possible explanation for an increase in flexural strength is that the significant residual or continued polymerization mediated by chemical reactive system occurred for these cement specimens as a radical polymerization process is diffusion controlled. This phenomenon could lead to an increased degree of cross-linking within the material with decreasing 
time and thereby leading to increased flexural strength. Also, according to Lu et al, ${ }^{12}$ the form of initiator system used had a considerable effect on the flexural strength of the resin luting agents. When two initiator systems are used, better polymerization is achieved for the dual-polymerized study samples. Thus, they concluded that dual-cure luting agents must be light initiated to achieve better mechanical properties.

From the present study, it can be inferred that both the dual-cure resin cements have clinically acceptable flexural strength as per the guidelines of ISO $4049,{ }^{13}$ whereas the resin-modified GIC lacks the clinical acceptance levels. The initial flexural strength of the self-etch, self-adhesive resin cement (MaxcemElite) was found to be higher than the self-adhesive resin cement (URC). However, after 24 hours of storage in saliva, the flexural strength and modulus of elasticity of both the cements increased as compared to their initial strengths, with Maxcem Elite being the better. Clinically, this may imply that in situations where more bending forces are anticipated such as long-span fixed dental prosthesis or where restoration is lacking sufficient resistance and retention form, cements with higher immediate flexural strength and modulus of elasticity may be indicated.

\section{Conclusion}

Within the limitations of the present study, it was concluded that:

1. The overall mean flexural strength and modulus of elasticity of resin-modified GIC were less than the clinically acceptable range under the test conditions.

2. The mean flexural strength and modulus of elasticity of resin-modified GIC reduced when the samples were tested after 24 hours of storage in saliva.

3. Both the dual-cure cements when cured through porcelain showed reduction in mean flexural strength and modulus of elasticity.

4. Among the two dual-cure resin cements Maxcem Elite, self-etch, self-adhesive resin cement showed better overall mean flexural strength as compared to URC when they were cured through porcelain and tested after 24 hours of storage in water.

5. Among the two dual-cure resin cements, URC showed superior but comparable results of modulus of elasticity to Maxcem Elite when they were cured through porcelain and tested after 24 hours of storage in water.
6. When comparing all three cements after 24 hours of storage, dual-cure cements showed better flexural strength and modulus of elasticity compared to resin-modified GIC.

\section{Source of Funding}

None.

\section{Conflict of Interest}

None declared.

\section{References}

1 Anusavice KJ, Shen C, Rawls HR, eds. Phillips's cience of Dental Materials. St. Louis, MO: Elsevier Health Sciences; 2012

2 Li ZC, White SN. Mechanical properties of dental luting cements. J Prosthet Dent 1999;81(5):597-609

3 Diaz-Arnold AM, Vargas MA, Haselton DR. Current status of luting agents for fixed prosthodontics. J Prosthet Dent 1999;81(2):135-141

4 El-Mowafy OM, Rubo MH. Influence of composite inlay/onlay thickness on hardening of dual-cured resin cements. J Can Dent Assoc 2000;66(3):147

5 Attar N, Tam LE, McComb D. Mechanical and physical properties of contemporary dental luting agents. J Prosthet Dent 2003;89(2):127-134

6 Bhamra GS, Fleming GJ. Effects of halogen light irradiation variables (tip diameter, irradiance, irradiation protocol) on flexural strength properties of resin-based composites. J Dent 2008;36(8):643-650

7 Meng X, Yoshida K, Atsuta M. Influence of ceramic thickness on mechanical properties and polymer structure of dual-cured resin luting agents. Dent Mater 2008;24(5):594-599

8 Blackman R, Barghi N, Duke E. Influence of ceramic thickness on the polymerization of light-cured resin cement. J Prosthet Dent 1990;63(3):295-300

9 Wadambe TN, Maheswari BU, Devarhubli AR. Comparison of sorption, solubility, and flexural strength of four resin luting cements in three different media: an in vitro study. Journal of Advanced Clinical and Research Insights. 2017;4(1):8-12

10 Yap AU. Resin-modified glass ionomer cements: a comparison of water sorption characteristics. Biomaterials 1996;17(19):1897-1900

11 Pace LL, Hummel SK, Marker VA, Bolouri A. Comparison of the flexural strength of five adhesive resin cements. J Prosthodont 2007;16(1):18-24

$12 \mathrm{Lu} \mathrm{H}$, Mehmood A, Chow A, Powers JM. Influence of polymerization mode on flexural properties of esthetic resin luting agents. J Prosthet Dent 2005;94(6):549-554

13 std . ISO 4049. International Standard Dentistry. Resin-based dental filling materials. 1988:1-7/std 